\title{
With Age Comes ...? An Examination of Gendered Differences in the Resource Advantages Associated with Parental Age in Norway
}

\author{
Wendy Sigle, Øystein Kravdal
}

\begin{abstract}
Using high-quality register data, this paper constructs an empirical portrait of older parenthood in contemporary Norway and explores gender differences in the extent to which older parents are better-resourced parents. Like most family issues, academic and policy discussions of older parenthood have tended to focus on the experiences of women. Although motherhood at older ages was not uncommon in previous generations, rapid social and family changes in recent decades mean that today's older mother is far more likely to be having her first child. She may have focused on obtaining a good education and then on establishing her career and finding a supportive partner. When viewed through this motherhood lens, older parents are often portrayed as being relatively well-off financially and enjoying stable family lives. Viewed through the fatherhood lens, however, the family literature suggests that age might not be as strong a marker of socio-economic advantage. Our findings show that this is the case: While older fathers are, on average, more socio-economically advantaged than younger fathers around the time their children are born, their relative advantage is narrower than what we observe when older mothers and younger mothers are compared. Gender differences in the family history profiles of older parents appear to explain some of the differentials we document. The children of older fathers are more likely to be born into blended families and less likely to born to a mother who postponed her first birth than are the children born to older mothers. The results suggest that the meaning of paternal age and maternal age differs: paternal age is not as strong a marker of socio-economic advantages and resources for children as maternal age is.
\end{abstract}

Keywords: Fertility postponement $\cdot$ Late parenthood $\cdot$ Fathers $\cdot$ Norway $\cdot$ Family Diversity 


\section{Introduction}

In many countries of Northern and Western Europe, the period since the late 1960s has been marked by dramatic and interrelated changes in fertility and family life. Cohabitation increasingly replaced marriage as the first union, and unmarried childbearing lost much of its stigma - particularly in contexts in which unmarried parents tended to co-reside. At the same time, opportunities for women to participate in higher education and the labour market created incentives for women to make use of new contraceptive technologies and to delay the transition to motherhood (Goldin 2006). Divorce and dissolution displaced widowhood as the predominant pathway into lone parenthood, and the subsequent formation of new partnerships resulted in growing numbers of blended families. These changes and their consequences, which have been collectively described in the demographic literature as the Second Demographic Transition (SDT) (Lesthaeghe 1995; van de Kaa 1994), have attracted considerable international interest amongst academics, policymakers, and social commentators.

For a variety of practical, pragmatic, and sometimes problematic reasons, social scientists have historically tended to approach the study of family changes by focusing almost exclusively on the experiences of women (Goldscheider/Kaufman 1996; Kneale/Joshi 2008; Lappegård et al. 2011; Sigle-Rushton 2005). Although demographers and family scholars increasingly recognise the theoretical and practical importance of carrying out research on men and fathers (Sigle-Rushton et al. 2013), the legacy of this focus on the experiences of women might mean that prevailing conceptual frameworks are less well-suited for depicting what has been going on with men. As feminist scholars confronted with androcentric bias in their fields of study have long noted, excavating the experiences of women is often challenging because existing frameworks and models do not always represent or explain their lived experiences well. In the study of family and fertility, we might encounter the same problem in reverse: When turning our attention from mothers to fathers, it might not be sufficient to simply "add men and stir". This may well be the case when we attempt to understand trends towards older parenthood in postSDT countries. The influential Diverging Destinies framework (McLanahan 2004) - and particularly the relationship between parental age and family resources that is central to it - may not fit the experiences of men as well as it fits the experiences of women. Moreover, the Norwegian context might differ from the Anglo-Saxon settings in pertinent ways. With lower income inequality and more generous parental leave policies the Norwegian economy may not differentially reward highly skilled women who delay childbearing to the same extent (Sigle 2016; Mandell Shalev 2009).

Although motherhood at older ages was not uncommon in previous generations, rapid social and family changes in recent decades mean that today's older mother is far more likely to be having her first child. She may have focused on obtaining a good education and then on establishing her career and finding a supportive partner. When viewed through this motherhood lens, older parents are often portrayed - in the social scientific literature at least - as being relatively well-off financially and 
enjoying stable family lives (Goisis et al. 2017; Goisis/Sigle 2014). Viewed through the fatherhood-lens, however, age might not be as strong a marker of socio-economic advantage and resources for children. Some older fathers will be having children at an advanced age because they are forming or completing their first family with a mother who postponed her first birth, and so resemble older mothers as described in the Diverging Destinies framework. However, there are reasons to think that a smaller percentage of older fathers than older mothers will have followed this family trajectory. Evidence has shown that the likelihood of forming a second family is higher for men than for women (Van Bavel et al. 2012; Ivanova et al. 2013) and we expect to see more older fathers than older mothers in second and higher order partnerships. Given that divorce, particularly when children are involved, is a "stratified and stratifying life event" (Raley/Sweeney 2020: 81; see also Sweeney 2010; for Norway, see Lappegård/Rønsen 2013; Poortman/Lyngstad 2007; Steele et al. 2009), this suggests that more older fathers than older mothers will be socioeconomically disadvantaged. As men tend to form partnerships with women who are younger than they are (Ní Bhrolcháin 2005) and wide age differences are often acceptable to both older men and younger women (Ní Bhrolcháin/Sigle-Rushton 2005), age differences are greater in subsequent partnerships (e.g. Ní Bhrolcháin 2005; Gustafson/Fransson 2015). We therefore expect older fatherhood to be less strongly associated with maternal postponement (having a partner who postponed her first birth) - and all its associated advantages - than older motherhood. Taken together, these gender differences suggest that older fatherhood will not be the same marker of resources for children as older motherhood is (McLanahan 2004). In other words, what measures of parental age represent - their meaning - may be gendered. We are, however, not aware of any studies that have systematically compared gender differences in the meaning of parental age.

Using high-quality Norwegian register data, this paper will begin to address this research gap. Our aims are to describe what distinguishes men registered as fathers at an older age $(40+)$ from men registered as fathers at a younger age in the same time period, to explore whether the differentials and trends are similar to what is observed when older (aged $36+$ ) and younger mothers are compared, and to document whether these gender differences have changed over the course of the SDT. Our findings represent a first step towards understanding whether advanced paternal age is, on balance, a similar marker of higher parental resources (McLanahan 2004) as maternal age is.

\section{Background and research questions}

Efforts to document, describe and explain older childbearing, which is typically defined as childbearing after age 35 or 40 , have, like fertility studies in general, tended to analyse the experiences of women (for an excellent recent exception, see Beaujouan 2020). In post-SDT countries, the increasing share of older mothers is often understood as being driven by economic or other incentives for a woman to have her first child at a later age (Billari et al. 2007). Historically, many older 
mothers were completing larger-than-average families that they started at younger ages. When fertility fell to low levels, most women who started their childbearing at young ages completed their families while they were still relatively young, and older motherhood became increasingly rare. In recent years, the number and share of older mothers has increased as women started and completed their childbearing closer to the biological limit (Goisis et al. 2017). Consequently, recent trends in older motherhood have been understood as a consequence of the process of maternal postponement.

The predominant focus on women in fertility studies and the emphasis on maternal postponement as the main driver of the growing share of older mothers has shaped the way the needs of families with older parents are represented and understood. Economists and demographers have tended to conceptualise contemporary, postponement-driven older motherhood as the avoidance and reversal of the disadvantages associated with early motherhood. Compared to early motherhood, postponement is associated with higher socio-economic status, greater maturity and a lower likelihood of dissolution, and so older motherhood is frequently described as both a marker and driver of advantage, with important implications for children and their life chances (Gustafsson 2001; McLanahan 2004). Consequently, on average, "an increase in mother's age is viewed as an increase in parental resources" (McLanahan 2004: 609).

In the demographic and sociological literature, concerns about early motherhood have tended to focus on socio-economic disadvantages, while studies of late motherhood, if they focus on risks at all, tend to focus on issues associated with biological constraints, health risks (Sobotka 2010), and the economic costs to wider society: subfecundity leading to eventual childlessness and fuelling low fertility rates in ageing societies, and the medical costs of providing ART to older women. Although some recent work has demonstrated that late motherhood may violate wider social norms and so attract some level of opprobrium (Billari et al. 2011), the assumption that older mothers are, on average, better-resourced mothers underpins much of the social scientific literature (Goisis/Sigle 2014). Even if evidence suggests that advanced maternal age means higher resources, should we assume that advanced paternal age can be interpreted similarly? This is our first research question.

Because men tend to be slightly older than their wives and partners, many men will become older fathers because they are having children with women who postponed their first birth (Henwood et al. 2011). Patterns of assortative mating and hypergamy suggest that these men will be similarly socio-economically advantaged. They may also have benefited from their partner's postponement by having more time to invest in their own education and career before assuming the responsibilities of fatherhood. However, family changes that accompanied the SDT suggest that the family and partnership histories may be more varied for older fathers than for older mothers, and in ways that suggest less socio-economic advantage. Previous studies have shown that men repartner more often and more rapidly than women do, especially when they are older and have had children in a previous union (Van Bavel et al. 2012; Ivanova et al. 2013). Consequently, we expect that older fathers 
will be more likely than older mothers to have to provide time and resources to dependent children from previous partnerships.

As age differences tend to be narrowest in first partnerships (Gustafson/ Fransson 2015), a greater share of second and higher order partnerships may lead to childbearing where the father, but not the mother, is becoming a parent at an older age. Taken together, this evidence suggests that some older fathers will be having children with mothers who have not postponed their first birth and, importantly, many of these men will not be first-time fathers. The literature on childbearing across partnerships suggests that these fathers are often more socio-economically disadvantaged than fathers who have children with only one partner (Lappegård/ Rønsen 2013; Ginther et al. 2019). However, few studies of multiple partner fertility link it to the rise in older parenthood more generally. Our second research question asks whether and how the families of older fathers and older mothers have differed in recent decades. To answer this question, we examine how older fathers and older mothers are distributed across five family history profiles that take into account maternal postponement and childbearing across partnerships. Our third research question asks whether the five family profiles are associated with differences in socioeconomic and health resources.

In contrast to the academic literature on older and late parenthood which has focused extensively on the postponement of first births to women, the "start-over" or "do it again" dad - an older man in a higher order partnership who starts a second family after his children from previous partnerships attain adulthood - figures prominently in media depictions of older fathers (Rubin 2016). This older father is often represented as a deeply committed family figure who regrets choices made the first time around, such as prioritizing work and earnings when his now adult children were younger. Like the mother who postpones, he is often assumed to be economically advantaged. However, he is consciously and actively embracing family life the second time around, often with a much younger partner who is starting her first family with him (Beyette 1985; Hartley 2014). Because media representations of this kind tend to be anecdotal, they provide little information about how typical this type of older father actually is. Furthermore, the start-over father has not attracted much attention in the academic literature, perhaps because of its (until recently) almost exclusive focus on women. "Start-over" parenthood - which requires that children from previous partnerships have all reached adulthood before starting a second family - represents a pathway that, for biological reasons, few women could follow into older motherhood, especially in recent decades as the proportion of women having their first birth in their early 20 s has declined substantially. This might explain why non-overlapping serial families have received limited attention in the extant literature so preoccupied with the experiences of women. Children born to such fathers might face less competition for time and resources from halfsiblings when they are young. However, they might also be born to the oldest of older fathers, and so we expect them to be more likely to experience the death of their father before they research adulthood.

Evidence that start-over fathers are, in line with media depictions, a distinct, more socio-economically advantaged group than other fathers with childbearing 
across partnerships would resonate with previous studies that found that, for Norwegian fathers, multiple partner fertility is associated not just with socioeconomic disadvantage (as shown in previous literature) but also with socioeconomic advantage (Lappegård/Rønsen 2013). When we answer our second and third research questions, we are specifically interested in examining the following: How typical and how distinct - from other kinds of blended families and other families with older parents - are families with older, start-over fathers?

\section{Data and Measures}

To examine differences between older fathers and mothers, we use data extracted from the Norwegian Population Register which covers everyone who has ever lived in the country after 1964. From this register we identified the mothers and fathers of children born in Norway in each of three time periods: 1991-95, 2001-05, and 201115. Individuals who became older parents in the first period would have reached adulthood during the early stages of Norway's SDT (Frejka 2017; Lesthaeghe 2011), while many of those who became older parents in the most recent period - except perhaps the very oldest fathers - became adults after the fertility and family changes that comprise the SDT were fairly well-advanced. For 98.2 percent of the children born, both the mother and father can be identified in the register. We excluded those cases where at least one parent was born before 1935 (less than 0.1 percent in the first period, otherwise 0.0 percent) because the birth histories of those parents may not be complete. Because birth events (deliveries) rather than children or parents are the unit of analysis, multiple births are treated as one event, and some parents are associated with more than one birth event in the analytic sample. This is the case for 12.9 percent of older fathers and 8.6 percent of older mothers.

For each delivery, we extracted information about the parents' ages at the time of delivery, the parents' ages at first birth, whether they had previously registered a birth with someone else, and the dates of any previous deliveries. For those deliveries that were recorded in the first time period, we extracted information about whether the parent died in the next 18 years, thus depriving the child of parental resources before they were legally independent. Furthermore, we added information about the highest educational level each of the parents had achieved, measured in the October before the year of birth, and the total pre-tax, pensionable income earned by each parent in the calendar year two years before the year of birth. This income measure includes wages and salaries, any income from self-employment, and unemployment benefits, temporary sickness benefits, and maternity or paternity benefits, but neither pensions nor permanent disability benefits.

For 7.1 percent of all deliveries in our sample, information about education was missing for either the mother or the father. This is often because the parent was born or educated abroad. In these cases, the delivery (the information for both parents) was excluded when average education levels were calculated.

Another limitation was that income was missing for many mothers or fathers. The missing value typically indicates that the parent did not earn any pensionable 
income that year. When there is no evidence that income was missing because the parent had been living abroad (3.8 percent of fathers and 8.8 percent of mothers), missing values were set to zero. When at least one parent was not living in Norway at the start of the previous two calendar years (8.1 percent of all deliveries), we excluded the delivery from all analyses of income differences. Finally, if at least one parent emigrated from Norway within 18 years of the delivery, that delivery is excluded from the analysis of survival/death.

We first consider whether, over the past three decades in Norway, older fathers can be described as better-resourced than younger fathers. We also consider whether the extent of any resource advantage is similar to what is observed when older mothers are compared to younger mothers. Older mothers are defined as those aged 36 and older. This is one year above the age threshold that is often used in the medical literature to classify a pregnancy as "geriatric", and so all of our older mothers were "geriatric" at conception. The literature offers little guidance about where to set the age threshold for older fathers. In their study of older firsttime fathers in Norway, Nilsen and colleagues (2013) used age 40 as the threshold for "very advanced age". In a cross-national comparison of late and "latest-late" parenthood in wealthy countries, Beaujouan (2020) used age 40/48 as the threshold for late/extremely late motherhood and $45 / 55$ as the threshold for late/extremely late fatherhood. In the absence of a clear convention, we relied primarily on information about the proportion of older mothers to set the age threshold for older fathers. Figure 1 shows the share of deliveries to all older parents (the height of the bars), and the share of all deliveries to "late" and "very late" parents. In the 201115 period, about 17 percent of mothers were aged $36+$ and therefore classified as older mothers. In the same period, a similar share of fathers was aged $40+$ (about 16 percent of fathers) and so we used this as the threshold for older fathers.

While our decision ensures that older parenthood, as we define it, is equally rare for both genders, there are differences and trends in the age distribution of older parents which may have implications for our results. To see these differences more clearly, Figure 2 shows how the older mothers and fathers are distributed across the late and extremely late age categories We use similar thresholds to those in Beaujouan (2020), with some slight adjustments so that the number of years of age included in the "late" category is the same for mothers (age 40-47) and fathers (age 44-51). While the majority of older parents in Norway are at the younger end of the age range, the share of older parents who are late or very late parents has increased over the time period our data covers: from 39 percent to 43 percent of deliveries to older fathers and from 19 percent to 25 percent of deliveries to older mothers. For men, the increase in the share of late fathers is observed mostly at ages 52+ ("extremely late"). In contrast, almost no Norwegian mothers have children at extremely late ages $(48+)$ and so the 6 percentage point increase in births to late mothers is observed almost exclusively in the 40-47 age group.

To measure fathers' and mothers' socio-economic position, we use information about their educational attainment and income. The first measure identifies individuals with higher tertiary education: an undergraduate degree and at least one year of graduate education. We focus on this relatively high level of attainment, 
Fig. 1: Percentage of deliveries to older parents (fathers $40+$, mothers $36+$ ), distinguishing late (fathers 44-51, mothers 40-47), and very late parents (fathers 52+, mothers 48+) in Norway

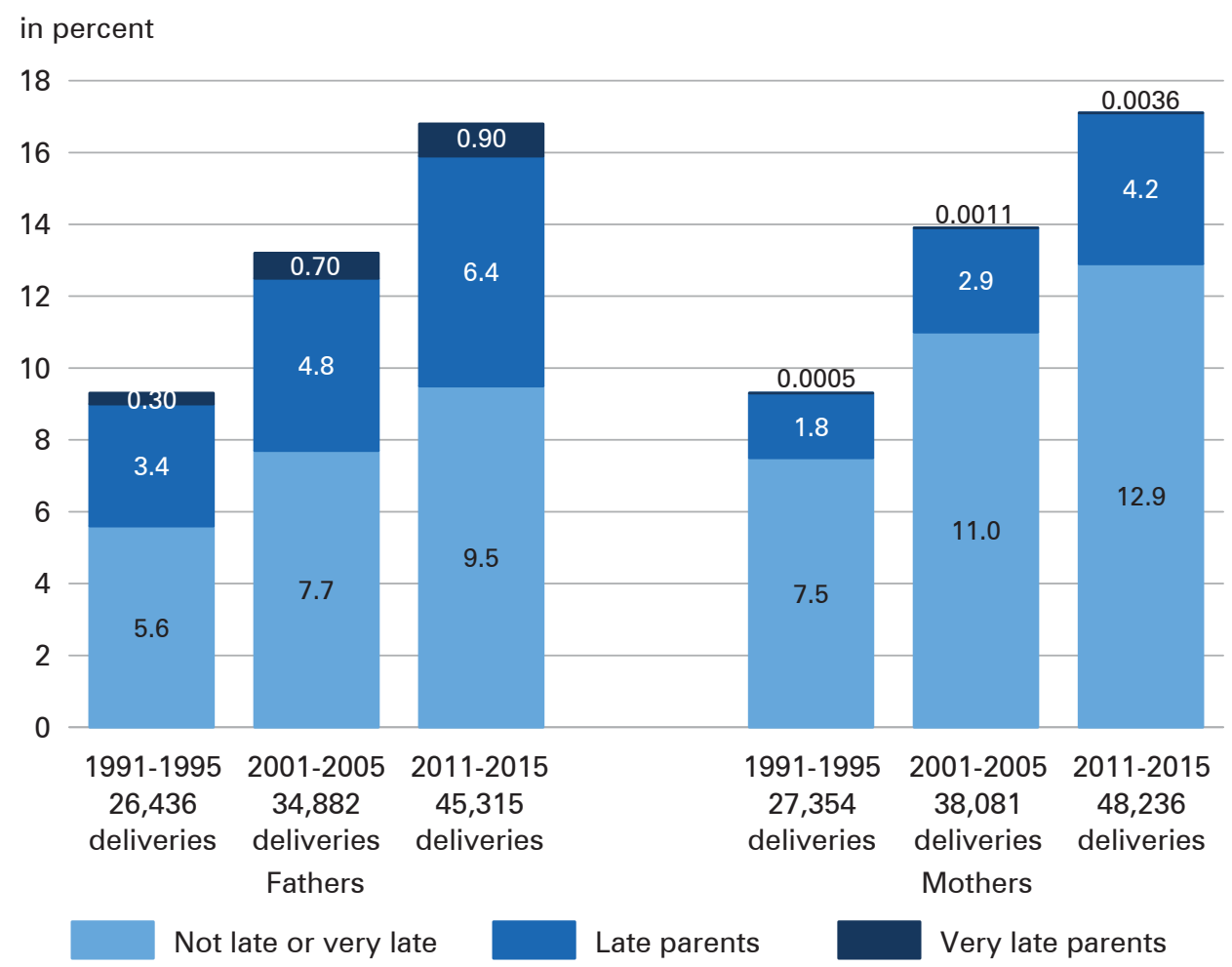

Source: Norwegian Population Register

equivalent to a Master's degree in many countries, because we cannot be certain that those recorded as having lower tertiary education completed their undergraduate degree. Because we are interested in whether older parents are better-resourced and whether the children born to older parents have greater access to economic resources, we examine both pensionable income and equivalised pensionable income (pensionable income divided by $1+0.3 k$ where $k$ represents the number of own biological children under the age of 18). We construct indicators for whether these income measures were in the top or bottom quartile of the respective income distribution of all fathers and all mothers who became parents in the same year (regardless of their age).

To account for blended families, we create an indicator that identifies fathers and mothers who have had children with more than one person. For parents who have registered a previous birth with another parent, we also calculated the time elapsed between the last child with a different parent and the first child with the current parent. We use this information to identify those fathers who completed their last family before starting their current family with a mother who had not previously 
Fig. 2: $\quad$ Percentage of older parents (fathers $40+$, mothers $36+$ ) that are late (fathers 44-51, mothers 40-47), and very late parents (fathers 52+, mothers 48+) in Norway

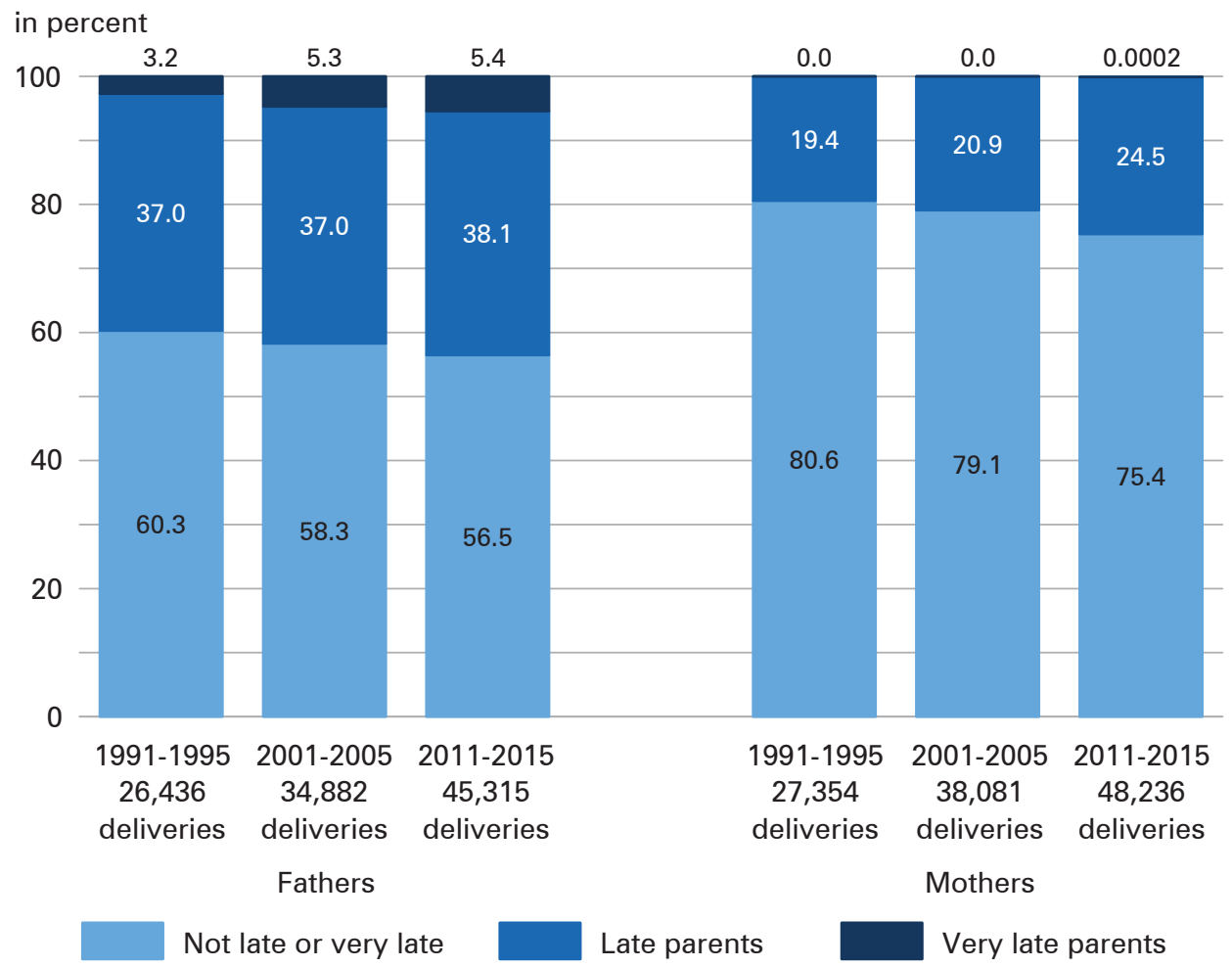

Source: Norwegian Population Register

had children. This means the youngest child with another parent was at least 18 before the father started his current family with a first-time mother. As noted above, for biological reasons, few women could become start-over mothers, especially in a context where few first births occur in the late teens and early 20s, and so we examine start-over father families only. ${ }^{1}$

To answer our second and third research questions, we move beyond individual circumstances of older parents and compare the distribution of older parents across five family history profiles (research question 2) and examine how the characteristics and resources of parents vary across those profiles (research question 3). These profiles take into account whether the mother of the child postponed her first birth (already established as a clear marker of high resources e.g. McLanahan 2004), the presence of maternal and paternal half-siblings (often shown - or assumed - in

1 In all three periods, fewer than 1 percent of older mothers had started a new family with a firsttime father after all their children with other fathers reached 18. 
previous literature to be marker of lower resources; e.g. McLanahan 2004; Sweeney 2010) and whether the father who has previous children is a start-over father (less explored in the extant literature).

We first divide the sample into two groups: those children born with at least one half-sibling (maternal or paternal) and those children born to parents who have only had children with each other. From the first group, we identify the Start-Over Dad families: there are only paternal half-siblings, the youngest of which was at least 18 when the parents had their first child together (the first full sibling or the delivery in our sample). Setting aside this Start-Over Dad group, the remaining two groups are each divided into families with and without maternal postponement. We consider motherhood to have been postponed when the first birth occurs after the age of 30. In recent decades, time spent in education has increased and other events that mark the transition to adulthood, including the age at first birth, have been delayed to older ages. The average age at first birth climbed from 26.1 in the early 1990s to 28.2 in 2010. By 2016, the average age at first birth for women in Norway was 29. Although the age 30 threshold is a bit lower than what has been used in recent Scandinavian medical studies (Waldenström 2016), it identifies women who, even in the most recent period, were having their first birth later than average and who had sufficient time to complete high levels of education and get established in their careers before transitioning to motherhood. This classification approach results in five mutually exclusive family history profiles.

The first family history profile, Diverging Destinies, identifies families where the mother postponed her first birth (beyond age 30) and there are no maternal or paternal half-siblings. This profile most closely resembles the high resource life course trajectory described by Sara McLanahan (2004) in her Diverging Destinies framework. The second family history profile, pre-SDT, most closely resembles the normative family patterns of the mid- $20^{\text {th }}$ century. It identifies those families where the mother did not postpone her first birth and there are no half-siblings. In many of these families, both parents were relatively young when their first child was born. All of the children born to older mothers in the pre-SDT profile will therefore be higherorder births. In contrast, some of older fathers in this group will be having their first child with a much younger mother (8 percent, 11 percent and 14 percent in 1991-95, 2001-05, and 2011-15, respectively). The third family history profile identifies the Start-Over Dad families. There are only paternal half-siblings, and the youngest halfsibling was at least 18 before the father and mother had their first child. The fourth and fifth family history profiles contain all the remaining families with at least one half-sibling. The fourth profile, Early Sequential Parenting, includes mothers who did not postpone their first birth, and the fifth profile, Late Sequential Parenting, includes mothers who did.

As both early parenting and family complexity have been shown to be associated with greater disadvantages, we expect the Diverging Destinies families to be most advantaged and the Early Sequential Parenting profile to be most disadvantaged. We expect the pre-SDT and Late Sequential Parenting family history profiles to fall in between the two extremes. Because media depictions of Start-Over Dad families as highly resourced are anecdotal, we examine whether, in a representative sample, 
these families have greater resources available to children than other kinds of stepfamilies.

\section{$4 \quad$ Results}

Our first research question asks whether older fatherhood is as strong a marker of high (individual-level) resources as older motherhood is. Table 1 presents information on the socio-economic position of older and younger parents as well as information about the economic resources they can provide for their children. For each of the three time periods, we first compare older fathers and mothers to their younger counterparts and then examine whether, drawing on what we know about gendered differences in family patterns and trends, those age-related differentials are narrower for fathers than for mothers at different points in time.

The figures in Table 1 indicate that both older fathers and older mothers are relatively more educated than younger fathers and mothers respectively. Since the early 1990s, however, the share of all parents with a tertiary qualification has increased, and educational differences between older and younger parents have become less pronounced, with the largest change occurring between the first and second period. In the early 1990s, older fathers were more than twice as likely as younger fathers to have higher tertiary education. Ten years later, they were just 35 percent more likely than younger fathers to have a postgraduate qualification. In all three periods, the relative educational advantage is greater for older mothers than for older fathers. For the 2011-15 period, older mothers were 71 percent more likely than younger mothers to have obtained a postgraduate qualification. In the same period, older fathers were only 20 percent more likely than younger fathers to have higher tertiary education.

Both older fathers and older mothers are over-represented in the top quartile and under-represented in the bottom quartile of pensionable income in all three time periods. However, the over-representation is most marked in the earliest period for older fathers, when 41.5 percent had pensionable income in the top quartile of the income distribution (of all fathers of newborns in the same year) and in the most recent period for older mothers, when 43.5 percent had a pensionable income in the top quartile of the mothers' income distribution.

Because income tends to increase with age, the differences in pensionable income between older and younger parents are not surprising. However, as the next rows of Table 1 show, older parents are less likely than younger parents to be having their first birth and more likely to have larger families. While declining over time, in the most recent period, 20.4 percent of the older fathers had at least three previous children, compared to only 3.2 percent of fathers younger than 40 . Older mothers are also more likely than younger mothers to have large families. However, the percentage of older mothers with three or more previous births is, in all periods, substantially smaller than the percentage of older fathers with at least three previous births. In the most recent period, for example, only 13 percent of older mothers have already had three or more children. These figures suggest that 
Tab. 1: Socio-economic and health resources of older and younger parents in Norway

\begin{tabular}{|c|c|c|c|c|c|c|c|}
\hline & $\begin{array}{c}\text { Fathers } \\
40+ \\
(\%)\end{array}$ & $\begin{array}{c}\text { Fathers } \\
<40 \\
(\%)\end{array}$ & $\begin{array}{l}\text { Older: } \\
\text { Younger } \\
\text { Fathers }\end{array}$ & $\begin{array}{c}\text { Mothers } \\
36+ \\
(\%)\end{array}$ & $\begin{array}{c}\text { Mothers } \\
<36 \\
(\%)\end{array}$ & $\begin{array}{l}\text { Older: } \\
\text { Younger } \\
\text { Mothers }\end{array}$ & $\begin{array}{l}\text { Fathers' } \\
\text { ratio: } \\
\text { Mothers' } \\
\text { ratio }\end{array}$ \\
\hline \multicolumn{8}{|c|}{ Older Parents } \\
\hline $1991-95$ & 9.0 & 91.0 & 0.10 & 9.3 & 90.7 & 0.10 & 0.96 \\
\hline $2001-05$ & 12.7 & 87.3 & 0.15 & 13.9 & 86.1 & 0.16 & 0.90 \\
\hline $2011-15$ & 16.1 & 83.9 & 0.19 & 17.1 & 82.9 & 0.21 & 0.93 \\
\hline \multicolumn{8}{|c|}{ Educational Qualifications } \\
\hline \multicolumn{8}{|c|}{ Higher tertiary } \\
\hline 1991-95 & 13.6 & 6.7 & 2.03 & 7.0 & 2.8 & 2.50 & 0.81 \\
\hline $2001-05$ & 13.6 & 10.1 & 1.35 & 12.8 & 7.1 & 1.80 & 0.75 \\
\hline $2011-15$ & 17.5 & 14.6 & 1.20 & 24.3 & 14.2 & 1.71 & 0.70 \\
\hline \multicolumn{8}{|c|}{ Own Pensionable Income } \\
\hline \multicolumn{8}{|c|}{ Bottom quartile of parents of children born in the same year } \\
\hline 1991-95 & 18.8 & 25.6 & 0.73 & 19.6 & 25.5 & 0.77 & 0.96 \\
\hline $2001-05$ & 22.2 & 25.4 & 0.87 & 17.8 & 26.2 & 0.68 & 1.29 \\
\hline $2011-15$ & 20.1 & 25.9 & 0.78 & 14.7 & 27.2 & 0.54 & 1.44 \\
\hline \multicolumn{8}{|c|}{ Top quartile of parents of children born in the same year } \\
\hline 1991-95 & 41.5 & 23.4 & 1.77 & 40.3 & 23.4 & 1.72 & 1.03 \\
\hline $2001-05$ & 35.5 & 23.5 & 1.51 & 39.1 & 22.7 & 1.72 & 0.88 \\
\hline $2011-15$ & 35.8 & 23.0 & 1.56 & 43.4 & 21.1 & 2.06 & 0.76 \\
\hline \multicolumn{8}{|c|}{ Number of Own Previous Children } \\
\hline \multicolumn{8}{|c|}{ No previous births } \\
\hline $1991-95$ & 14.4 & 44.2 & 0.33 & 15.5 & 44.4 & 0.35 & 0.93 \\
\hline $2001-05$ & 18.6 & 45.4 & 0.41 & 19.2 & 45.3 & 0.42 & 0.97 \\
\hline 2011-15 & 21.7 & 47.2 & 0.46 & 23.0 & 47.3 & 0.49 & 0.95 \\
\hline \multicolumn{8}{|c|}{ Three or more previous births } \\
\hline $1991-95$ & 31.2 & 5.0 & 6.24 & 23.2 & 4.1 & 5.66 & 1.10 \\
\hline $2001-05$ & 26.3 & 4.3 & 6.12 & 18.0 & 3.8 & 4.74 & 1.29 \\
\hline 2011-15 & 20.4 & 3.2 & 6.38 & 13.0 & 2.9 & 4.48 & 1.42 \\
\hline \multirow{2}{*}{\multicolumn{8}{|c|}{$\begin{array}{l}\text { Equivalised Own Income (dependent children only, children } 18+\text { excluded) } \\
\text { Bottom quartile of parents of children born in the same year }\end{array}$}} \\
\hline & & & & & & & \\
\hline $1991-95$ & 23.3 & 25.2 & 0.92 & 21.3 & 25.4 & 0.84 & 1.10 \\
\hline $2001-05$ & 28.5 & 24.5 & 1.16 & 20.5 & 25.7 & 0.80 & 1.46 \\
\hline $2011-15$ & 25.5 & 24.9 & 1.02 & 17.7 & 26.6 & 0.67 & 1.54 \\
\hline \multicolumn{8}{|c|}{ Top quartile of parents of children born in the same year } \\
\hline $1991-95$ & 32.2 & 24.3 & 1.33 & 29.3 & 24.6 & 1.19 & 1.11 \\
\hline $2001-05$ & 28.2 & 24.6 & 1.15 & 29.6 & 24.2 & 1.22 & 0.94 \\
\hline $2011-15$ & 29.6 & 24.1 & 1.23 & 34.0 & 23.1 & 1.47 & 0.83 \\
\hline \multicolumn{8}{|c|}{ Died Within 18 Years of the Birth ${ }^{\mathrm{a}}$} \\
\hline $1991-95$ & 6.8 & 2.1 & 3.24 & 2.1 & 0.9 & 2.30 & 1.39 \\
\hline
\end{tabular}

a Amongst those parents who did not permanently emigrate.

Source: Norwegian Population Register and registers on education and income 
age-related economic advantages observed using pensionable income will narrow when equivalised income is used. They also suggest that the results will change more for fathers than for mothers.

When income is equivalised to account for the number of dependent children, older parents are still over-represented in the top quartile, but, as expected, the difference narrows. At the bottom end of the distribution, older mothers are less likely to have a bottom-quartile income in all three periods, and this is most pronounced in the most recent period. In contrast, older fathers are under-represented in the bottom quartile of the equivalised income distribution in the first period only.

To the extent that higher educational attainment or a top-quartile equivalised income are valid indicators of high levels of resources for children born in Norway, the figures in Table 1 suggest that older fathers are better-resourced than younger fathers, but the association of parental age and high resources is stronger for mothers than for fathers. Moreover, the strength of the relationship between paternal age and resources for children declined over the three periods as enrolment in higher education has increased and childbearing has shifted to older ages more generally. For older mothers, their income advantages - but not their educational advantages - have actually widened. We interpret older mothers' improved position in the equivalised income distribution across the three time periods as an upward trend in the economic resources they have available for their children. The results for older fathers suggest an opposite trend.

Regardless of their age, few parents of children born in the early 1990s died within 18 years. Nonetheless, older parents were more likely to die than younger parents. Unsurprisingly, given their higher average age (Table 1) and more skewed age distribution (Fig. 2), the absolute and relative risk of death was highest for older fathers, who were 3.2 times as likely to die as fathers who were under age 40 . Around 6.8 percent of older fathers who did not emigrate (and so were excluded from the analysis) did not survive. The risk of death for younger fathers and older mothers was similar: around 2 percent died within 18 years.

The individual characteristics of older parents suggest that parental age is a marker of resources for children, but that maternal age is a stronger marker than paternal age is. When considering the resources available to children, and the extent to which they vary by parental age, the characteristics of both parents are relevant. To consider whether and how the parental characteristics of children born to older fathers and older mothers differ in ways that might suggest higher or lower resources for their children, we next look at the distribution of older fathers and older mothers across the five family history profiles. As described in the data and methods section, these five profiles are constructed by cross-tabbing maternal postponement (the older mother postponed or the older father is having a child with a mother who postponed her first birth) and family complexity (the presence of one or more half-siblings), and then separating out, as a fifth profile, those deliveries to blended families with start-over fathers.

Figure 3 shows how older fathers and older mothers are distributed over the five family history profiles and how the distributions have changed over time. The share of Diverging Destinies families (the mother postponed her first birth, and neither 
Fig. 3: Family history profiles of older fathers and older mothers in Norway, 1991-2015

Older Fathers $\quad$ Older Mothers

in percent

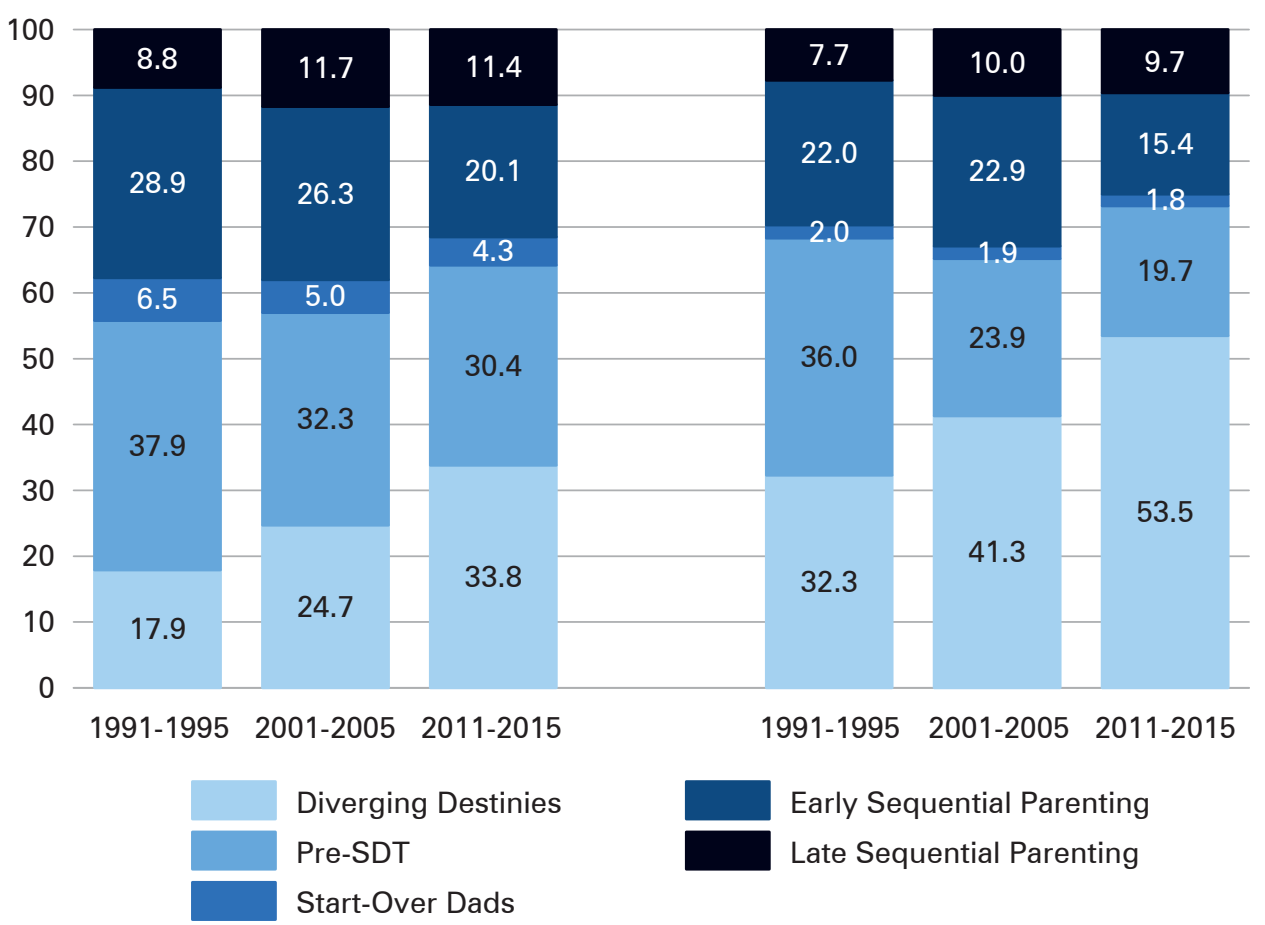

Source: Norwegian Population Register

parent has had a child with another person), which we hypothesised would contain the most advantaged older parents, has increased over time for both fathers and mothers. This profile became the modal profile of older mothers in the second period (41.3 percent of deliveries to older mothers), and by 2011-15, this profile accounted for the majority of the older mothers -53.5 percent. While increasing over the three time periods, the share of older fathers in such families is notably smaller. It is only in the most recent period that the Diverging Destinies profile becomes the modal family history profile for older fathers, accounting for 33.8 percent of the deliveries.

The pre-SDT family history profile was, in 1991-95, the modal family history profile for both older fathers (37.9 percent of birth events) and older mothers (36 percent of birth events). In subsequent periods, the share of children born into pre-SDT families declined, but more for older mothers than older fathers. In the final period, the Pre-SDT family history profile still accounted for 30.4 percent of the older fathers, but only 19.7 percent of older mothers.

The share of parents in the remaining three profiles - all of which involve some childbearing across partnerships - has declined over the three time periods. The 
latter trend is more pronounced for older fathers than older mothers. Nonetheless, in the most recent period, these three profiles contained a larger share of older fathers than older mothers, and so the children born to older fathers are more likely to have half-siblings than the children born to older mothers. Although the share of older fathers in the Late Sequential Parenting profile is larger, the percentage of older mothers in the Diverging Destinies profile is far larger, suggesting that older motherhood is more strongly associated with maternal postponement than older fatherhood is.

In the 2011-15 period, at least 63.2 percent of older mothers postponed their first birth and at least 45.2 percent of older fathers were having a child with a mother who postponed her first birth. We say "at least" because the Start-Over Dad profile contains mothers who postponed and mothers who did not postpone their first birth. For the 2011-15 period, only 4.3 percent of the older fathers were start-over fathers and 1.8 percent of the older mothers were having a child with a start-over father. ${ }^{2}$ Around 63 percent of these start-over dads are having a child with a mother who postponed her first birth (2.7 percent of deliveries to older fathers), while 89 percent of older mothers in Start-Over Dad families postponed their first birth (1.6 percent of deliveries to older mothers). Adding the percentage of Start-Over Dad families where the mother postponed her first birth thus has little impact: In total, 64.8 percent of children born to older mothers had a mother who postponed her first birth and $\mathbf{4 7 . 9}$ percent of children born to older fathers had a mother who postponed her first birth. That older motherhood is more strongly associated with maternal postponement than older fatherhood and that older fatherhood is more strongly associated with family complexity than older motherhood suggests differences in their family histories should partly explain why older motherhood is a stronger marker of socio-economic advantage and resources for children.

Turning to our third research question, Tables 2 and 3 present information on how parental characteristics and resources available to children with older fathers (Table 2) and older mothers (Table 3 ) vary across the five family history profiles. The Diverging Destinies profile often, but not always, includes the most highly resourced older parents. In all three time periods, older parents who meet the criteria for this family history profile are more likely to be highly educated and to be having a child with someone who is highly educated. These educational differentials are most pronounced in the most recent period. For two of the three time periods, the Diverging Destinies profile contains the smallest percentage of older fathers with a bottom-quartile, pensionable income. Differences from older fathers in the Late Sequential Parenting profile are, in all periods, small, and in the most recent period, the gap in bottom-quartile pensionable income is reversed. While the Diverging Destinies fathers were most likely to have a top quartile pensionable income (42 percent) in the most recent period, the Late Sequential Parenting profile was,

2 Since almost all start-over fathers are older fathers, these figures suggest that the majority of older fathers in the Start-Over Dad profile are having children with women who are not older mothers ([4.3 $\times 45,315$ deliveries $]-1.8 \times 48,236$ deliveries $] /[4.3 \times 45,315]=55$ percent $)$. 
378 - Wendy Sigle, Øystein Kravdal

Tab. 2: Socio-economic and health resources of older fathers by family profile

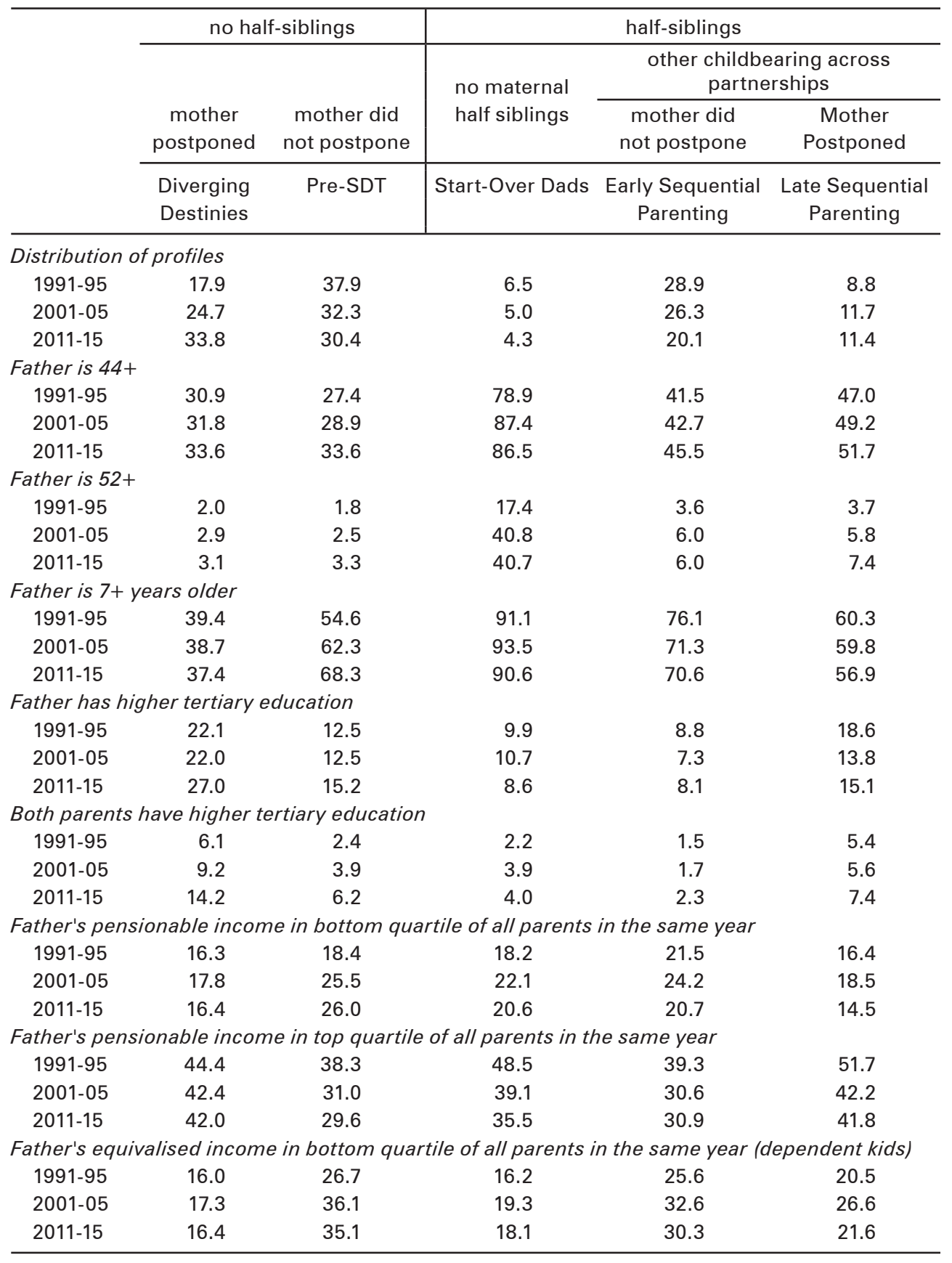


Tab. 2: Continuation

\begin{tabular}{|c|c|c|c|c|c|}
\hline & \multicolumn{2}{|c|}{ no half-siblings } & \multicolumn{3}{|c|}{ half-siblings } \\
\hline & \multirow[b]{2}{*}{$\begin{array}{c}\text { mother } \\
\text { postponed }\end{array}$} & \multirow[b]{2}{*}{$\begin{array}{l}\text { mother did } \\
\text { not postpone }\end{array}$} & \multirow{2}{*}{$\begin{array}{l}\text { no maternal } \\
\text { half siblings }\end{array}$} & \multicolumn{2}{|c|}{$\begin{array}{l}\text { other childbearing across } \\
\text { partnerships }\end{array}$} \\
\hline & & & & $\begin{array}{c}\text { mother did } \\
\text { not postpone }\end{array}$ & $\begin{array}{c}\text { Mother } \\
\text { Postponed }\end{array}$ \\
\hline & $\begin{array}{l}\text { Diverging } \\
\text { Destinies }\end{array}$ & Pre-SDT & Start-Over Dads & $\begin{array}{l}\text { Early Sequential } \\
\text { Parenting }\end{array}$ & $\begin{array}{l}\text { Late Sequential } \\
\text { Parenting }\end{array}$ \\
\hline \multicolumn{6}{|c|}{ Father's equivalised income in top quartile of all parents in the same year (dependent kids) } \\
\hline 1991-95 & 45.7 & 22.6 & 56.2 & 30.2 & 35.4 \\
\hline $2001-05$ & 41.3 & 19.3 & 44.9 & 23.8 & 27.6 \\
\hline 2011-15 & 41.8 & 19.6 & 43.9 & 23.0 & 26.6 \\
\hline \multicolumn{6}{|c|}{ Father's fourth or higher order birth } \\
\hline 1991-95 & 3.3 & 32.3 & 33.4 & 42.5 & 43.6 \\
\hline 2001-05 & 3.1 & 27.5 & 33.5 & 38.6 & 41.5 \\
\hline $2011-15$ & 2.3 & 22.6 & 30.0 & 36.5 & 36.7 \\
\hline \multicolumn{6}{|c|}{ Father died within 18 years of the birth ${ }^{a}$} \\
\hline 1991-95 & 6.4 & 6.3 & 10.4 & 7.8 & 7.2 \\
\hline
\end{tabular}

Notes: When a figure associated with profile $2,3,4$, or 5 is underlined, the difference with profile 1 is statistically significant at the 5 percent level. When the figure associated with profile 4 or profile 5 is in boldface, the difference with profile 3 is statistically significant at the 5 percent level. ${ }^{a}$ Amongst those who did not emigrate.

Source: Norwegian Population Register and registers on education and income

again, little different (41.8 percent). The pensionable incomes of Start-Over Dad families were, in all periods, more similar to the other two economically advantaged profiles, but they became less similar (less economically advantaged) over time.

Contrary to what we predicted, in all three time periods, the Late Sequential Parenting older mothers are least likely to have a bottom-quartile pensionable income and most likely to have a top-quartile pensionable income, although, at the top end of the earnings distribution, differences with the Diverging Destinies mothers narrowed substantially over time. In the 2011-15 period, the percentage with top-quartile pensionable income is roughly the same for both profiles. The relative economic advantage enjoyed by older mothers in Start-Over Dad families declined over the three time periods we consider, and by the final period, their pensionable income distribution was substantially different from older mothers in the Diverging Destinies and Late Sequential Parenting profiles.

When we consider economic resources available to children by equivalising older fathers' pensionable income, the Diverging Destinies and Start-Over Dad profiles are the most advantaged in all three periods, and the Late Sequential Parenting profile more closely resembles the two less-advantaged profiles (pre$S D T$ and Early Sequential Parenting). For older mothers, the figures for bottomquartile income are little changed when pensionable income is equivalised. At the 
top end of the distribution, older mothers in Start-Over Dad families do not become less advantaged over time relative to the Diverging Destinies and Late Sequential Parenting profiles as we observed with pensionable income. In all periods, the Diverging Destinies profile contains a lower share of top-quartile observations than the other two profiles, but the gap has narrowed substantially over time to around 5 percentage points in the most recent period. Taken together, these figures suggest that maternal postponement has remained persistently associated with socioeconomic advantage and resources for children, but the stratifying effects of family complexity depend to a greater extent on the measure of economic advantage that we use.

In contrast to media depictions of start-over dads, the results suggest higher resources for children not because their fathers have markedly higher incomes but because they have markedly fewer dependents than fathers in other kinds of stepfamilies. They are less likely to be having a fourth or higher order birth than other older fathers in complex families, and so have fewer dependents. Even so, we might ask whether we have underestimated the claims on their resources. Although not legally dependent, adult children might nonetheless make a substantial claim on their fathers' resources. This would not be reflected in our equivalised income measure, which did not count adult children as dependents. When we equivalise income using a count of all children regardless of their age (results not shown, but available upon request), older fathers in the Start-Over Dad profile no longer stand out as having greater resources for their children. ${ }^{3}$ They most resemble those older fathers in the Early Sequential Parenting profile. Start-over fathers are not more highly qualified than older fathers in other types of blended families either, and given their higher average age, they are the most likely to die within 18 years of the delivery (based on deliveries in the 1991-95 period only). Hence, it is not clear that older fathers in Start-Over Dad families provide, on average, greater resources for children.

\section{$5 \quad$ Discussion and Conclusion}

This paper takes as its point of departure previous research on the impact of family changes which have accompanied the SDT. Focusing predominantly on women's fertility and family experiences, and dramatic trends in the postponement of the transition to motherhood, the demographic literature has tended to use advanced maternal age as a marker of resources which benefit parents and children (McLanahan 2004). Drawing on previous research which has questioned whether demographic indicators like maternal age or marital status mean the same thing

3 Because few women who become older mothers have adult children, their income results do not change much when we count all children. Only those mothers in the Early Sequential Parenting profile (half-sibling(s) and the mother did not postpone) show any real change: They are slightly more likely to have a bottom-quartile income and slightly less likely to have a topquartile income when their income is equivalised using all children, dependent or otherwise. 
across different contexts or different population groups (Sigle/Goisis 2019), and inspired by feminist research which has noted that conceptual frameworks that were developed to explain the experiences of one gender (usually men) are often inadequate when the focus is shifted to the other gender, we ask whether and to what extent advanced paternal age means the same thing as advanced maternal age does. In other words, is it a similar marker of resources and advantages? We also examine how the resources associated with advanced paternal and maternal age have changed over the course of the SDT in Norway.

Using high-quality Norwegian register data covering three time periods, we find that around the time their children are born, older fathers (aged $40+$ ) tend to be better resourced than younger fathers are. They are more highly educated and, even taking into account the number of biological dependent children that require their support, their financial position tends to be better. However, their resource advantages have narrowed in recent decades. For most measures, the largest changes were observed from the first (1991-95) to the middle period (2001-05). An economic recession beginning in 1988 and affecting younger people more than older people might have exacerbated income differences in the first period. In addition, many older fathers in the early 2000s will have come of age prior to the rapid expansion of higher education (Aamodt/Arnesen 1995) which many of the younger parents they are compared to would have benefitted from.

When we examined whether the differentials and trends were similar to what is observed when older (aged $36+$ ) and younger mothers are compared, we found that maternal age tends to be consistently associated with more socio-economic advantage and more resources for children than paternal age is. Moreover, the age-related earned income advantage increased for older mothers and narrowed for older fathers over the three time periods. In the early 1990s, Norway was still often described as having a housewife model. However, policy developments in the 1980s had already initiated a move towards a dual-earner model (Lewis 1992; Frønes 1997). Older parents of children born in first period transitioned to adulthood at a time when policies and the wider culture did not support mothers' full-time employment (Ellingsæter/Jensen 2019). If highly educated older mothers in the later periods faced less statistical discrimination in the labour market than older mothers in the early period, highly educated mothers would be more likely to attain positions and pay commensurate with their education in recent years.

Differences in the family history profiles of older fathers and older mothers also appear to have contributed to the observed gender differences and trends. The more advantaged family history profiles contain a larger share of older mothers than older fathers, and these gender differences have widened over time. In the most recent period, the majority of older mothers in Norway followed what Sarah McLanahan (2004) described as a high resource trajectory: they had postponed their first birth (facilitating investments in education and career) and neither they nor their partner had children with someone else. Only about one-third of older fathers lived in such families. Older mothers are more likely to have postponed their first birth than are the partners of older fathers. 
We find weaker and more qualified evidence for the stratifying effects of family complexity. The older parents who followed the Late Sequential Parenting and Start-Over Dad trajectory are less educated than the Diverging Destinies parents, but their pensionable income distribution (Late Sequential Parenting) or equivalised income distribution (Start-Over Dad) is similar. When we take into account the number of dependent children, older fathers - but not older mothers - in the Late Sequential Parenting profile are less economically advantaged. Their relatively large family size means they have fewer economic resources available for their children. The Start-Over Dad fathers do not have higher pensionable incomes but, with fewer dependent children, they have more economic resources available for their child. When we consider all children rather than dependent children, older fathers in the Start-Over Dad profile no longer appear similar to the Diverging Destiny fathers. For older mothers, the results are less dependent on the indicator of economic resources we use, in part because older mothers in the Late Sequential Parenting profile do not have much larger families than the other profiles with relatively high pensionable incomes, and they are less likely to have adult children.

Taken together, the results illustrate important differences between older fathers and older mothers in contemporary Norway. While our findings suggest that regardless of gender, older parents are better resourced parents, they also indicate that the resource advantage is more pronounced for older mothers than older fathers. Some family history profiles are less socio-economically advantaged or well-resourced than others, and these profiles are more typical of older fathers than older mothers. If the family histories of older fathers and older mothers were more similar, gender differences in the extent to which parental age is a marker of socioeconomic advantage and resources for children would likely narrow. Nonetheless, some family history profiles are more strongly associated with advantage for older mothers than for older fathers, in part because the characteristics of the families differ when the focus is on older fathers. For example, older fathers in the Late Sequential Parenting profile are more likely than older mothers in the same profile to have at least four children, and so have greater claims on their resources.

Our results highlight the importance of examining the resources and family histories of both parents. The more complex family experiences of older fathers may have resource implications for the children born to older mothers. Although older mothers are less likely than older fathers to have had children with a previous partner, the share of older mothers who give birth to children with a half-sibling increases substantially when the family histories of the fathers are considered as well. In recent years (2011-15), about 15 percent of older mothers have had a child with a previous partner, but nearly 27 percent are having children with at least one half-sibling (results not shown but available upon request). The extent to which older parents must negotiate the costs and challenges associated with having had a previous family may be under-estimated when older parenthood is viewed exclusively through the lens of the mother's experiences (see also Cancian et al. 2011). At the same time, for older mothers, maternal postponement appears to be linked to more (maternal) resources even when half-siblings are present. Differences in the family histories of older fathers and older mothers underscore the need to 
attend carefully to what demographic indicators represent in a given context and for a given group.

\section{Acknowledgements}

The authors would like to thank the editors of Comparative Population Studies and three anonymous reviewers for extremely detailed, supportive, and thoughtful comments on earlier drafts of this paper. In addition, we benefitted from comments from Rebecca Sear and conversations with Adrienne Burgess. Any remaining errors are our own. This project was supported by the Research Council of Norway through its Centres of Excellence funding scheme, project number 262700.

\section{References}

Aamodt, Per Olaf; Arnesen, Clara Åse 1995: The Relationship Between Expansion in Higher Education and the Labour Market in Norway. In: European Journal of Education 30,1: 65-76. https://doi.org/10.2307/1503568

Beaujouan, Éva. 2020: Latest-Late Fertility? Decline and Resurgence of Late Parenthood Across the Low-Fertility Countries. In: Population and Development Review 46,2: 219247. https://doi.org/10.1111/padr.12334

Beyette, Beverley 1985: Fathers Who Know Best: Second Families for Mid-Life Dads. In: Los Angeles Times 16.6.1985 [https://www.latimes.com/archives/la-xpm-1985-06-16vw-2918-story.html, 12.7.2021].

Billari, Francesco C. et al. 2011: Social Age Deadlines for the Childbearing of Women and Men. In: Human Reproduction 26: 616-622. https://doi.org/10.1093/humrep/deq360

Billari, Francesco C. et al. 2007: Approaching the Limit: Long-Term Trends in Late and Very Late Fertility. In: Population and Development Review 33,1: 149-170. https://doi.org/10.1111/j.1728-4457.2007.00162.x

Cancian, Maria; Meyer, Daniel R.; Cook, Steven T. 2011: The Evolution of Family Complexity from the Perspective of Nonmarital Children. In: Demography 48,3: 957982. https://doi.org/10.1007/s13524-011-0041-4

Ellingsæter, Anne Lise; Jensen, Ragnhild Steen 2019: Politicising Women's Part-Time Work in Norway: A Longitudinal Study of Ideas. In: Work, Employment \& Society 33,3: 444-461. https://doi.org/10.1177/0950017018821277

Frejka, Tomas 2017: The Fertility Transition Revisited: A Cohort Perspective. In: Comparative Population Studies 42: 89-116. https://doi.org/10.12765/CPoS-2017-09

Frønes, Ivar 1997: The Transformation of Childhood: Children and Families in Postwar Norway. In: Acta Sociologica 40,1: 17-30. https://doi.org/10.1177/000169939704000102

Ginther, Donna K.; Grasdal, Astrid L.; Pollak, Robert A. 2019: Fathers' Multiple-Partner Fertility and Children's Educational Outcomes. NBER Working Papers 26242. National Bureau of Economic Research, Inc. [https://www.nber.org/papers/w26242, 12.7.2021].

Goisis, Alice; Sigle-Rushton, Wendy 2014: Childbearing Postponement and Child WellBeing: A Complex and Varied Relationship? In: Demography 51,5: 1821-1841. https://doi.org/10.1007/s13524-014-0335-4 
Goisis, Alice; Schneider, Daniel C.; Myrskylä, Mikko 2017: The Reversing Association Between Advanced Maternal Age and Child Cognitive Ability: Evidence from Three UK Birth Cohorts. In: International Journal of Epidemiology 46,3: 850-859. https://doi.org/10.1093/ije/dyw354

Goldin, Claudia 2006: The Quiet Revolution That Transformed Women's Employment, Education, and Family. In: American Economic Review 96,2: 1-21. https://doi.org/10.1257/000282806777212350

Goldscheider, Frances K.; Kaufman, Gayle 1996: Fertility and Commitment: Bringing Men Back In. In: Population and Development Review 22: 87-99. https://doi.org/10.2307/2808006

Goldscheider, Frances K.; Sass/er, Sharon 2006: Creating Stepfamilies: Integrating Children into the Study of Union Formation. In: Journal of Marriage and Family 68,2: 275-291. https://doi.org/10.1111/j.1741-3737.2006.00252.x

Gustafson, Per; Fransson, Urban 2015: Age Differences Between Spouses: Sociodemographic Variation and Selection. In: Marriage \& Family Review 51,7: 610 632. https://doi.org/10.1080/01494929.2015.1060289

Gustafsson, Siv 2001: Optimal Age at Motherhood. Theoretical and Empirical Considerations on Postponement of Maternity in Europe. In: Journal of Population Economics 14: 225-247. https://doi.org/10.1007/s001480000051

Hartley, Jo 2014: Meet the 'Start Over Dads'. In: Essentialbaby. [http://www. essentialbaby.com.au/just-for-you/relationships/meet-the-start-over-dads-2014052338sp9, 12.7.2021].

Henwood, Karen Linda; Shirani, Fiona; Procter, Joanne Kellett Nee 2011: On Delayed Fatherhood: The Social and Subjective Logics at Work in Men's Lives (A UK Study) In: Beets, Gijs; Schippers, Joop; te Velde, Egbert R. (Eds.): The Future of Motherhood in Western Societies: Late Fertility and its Consequences. Dordrecht: Springer: 159-175. https://doi.org/10.1007/978-90-481-8969-4_11

Hodges, Melissa J.; Budig, Michelle J. 2010: Who Gets the Daddy Bonus? Organizational Hegemonic Masculinity and the Impact of Fatherhood on Earnings. In: Gender \& Society 24,6: 717-745. https://doi.org/10.1177/0891243210386729

Ivanova, Katya; Kalmijn, Matthijs; Uunk, Wilfred 2013: The Effect of Children on Men's and Women's Chances of Re-Partnering in a European Context. In: European Journal of Population 29: 417-444. https://doi.org/10.1007/s10680-013-9294-5

Jansen, Mieke; Wijckmans, Belinda; Van Bavel, Jan 2009: Divorce and the Cumulated Fertility of Men and Women Across Europe. Interface Demography Working Paper 2009-1 [https://researchportal.vub.be/en/publications/divorce-and-the-cumulatedfertility-of-men-and-women-across-europ, 12.7.2021].

Jefferies, Julie; Berrington, Ann; Diamond, lan 2000: Childbearing Following Marital Dissolution in Britain. In: European Journal of Population 16: 193-210. https://doi.org/10.1023/A:1026529300659

Kneale, Dylan; Joshi, Heather 2008: Postponement and Childlessness - Evidence from Two British Cohorts. In: Demographic Research 19: 1935-1968. https://doi.org/10.4054/DemRes.2008.19.58

Lappegård, Trude; Rønsen, Marit; Skrede, Kari 2011: Fatherhood and Fertility. In: Fathering: A Journal of Theory, Research \& Practice about Men as Fathers 9,1: 103-120. https://doi.org/10.3149/fth.0901.103

Lappegård, Trude; Rønsen, Marit 2013: Socioeconomic Differences in Multipartner Fertility Among Norwegian Men. In: Demography 50,3: 1135-1153. https://doi.org/10.1007/s13524-012-0165-1 
Lesthaeghe, Ron 1995: The Second Demographic Transition in Western Countries: An Interpretation. In: Mason, Karen Oppenheim; Jensen, An-Magritt (Eds.): Gender and Family Change in Industrialized Countries. Oxford: Clarendon Press: 17-62.

Lesthaeghe, Ron 2011: The "Second Demographic Transition": A Conceptual Map for the Understanding of Late Modern Demographic Developments in Fertility and Family Formation. In: Historical Social Research / Historische Sozialforschung 36,2: 179-218. https://doi.org/10.12759/hsr.36.2011.2.179-218

Lewis, Jane 1992: Gender and the Development of European Welfare Regimes. In: Journal of European Social Policy 2,3: 159-173. https://doi.org/10.1177/095892879200200301

Mandel, Hadas; Shalev, Michael 2009: Gender, Class, and Varieties of Capitalism. In: Social Politics 16,2: 161-181. https://doi.org/10.1093/sp/jxp006

McLanahan, Sara 2004: Diverging Destinies: How Children are Faring Under the Second Demographic Transition. In: Demography 41,4: 607-627.

https://doi.org/10.1353/dem.2004.0033

Ní Bhrolcháin, Máire 2005: The Age Difference at Marriage in England and Wales: A Century of Patterns and Trends. In: Population Trends 120: 7-14.

NíBhrolcháin, Máire; Sigle-Rushton, Wendy 2005: Partner Supply in Britain and the US: Estimates and Gender Contrasts. In: Population 60,1-2: 37-64. https://doi.org/10.2307/4148201

Nilsen, Anne Britt Vika et al. 2013: Characteristics of First-Time Fathers of Advanced Age: A Norwegian Population-Based Study. In: BMC Pregnancy and Childbirth 13,1: 29-40. https://doi.org/10.1186/1471-2393-13-29

Office for National Statistics (ONS) 2002: Birth Statistics, Series FM1, no 31. [https://data. gov.uk/dataset/5eeb4c4a-6566-4fa3-a7d1-40b1cac41e78/birth-statistics-englandand-wales-series-fm1, 12.7.2021].

Poortman, Anne-Rigt; Lyngstad, Torkild H. 2007: Dissolution Risks in First and Higher Order Marital and Cohabiting Unions. In: Social Sciences Research 36: 1431-1446. https://doi.org/10.1016/j.ssresearch.2007.02.005

Presser, Harriet B. 1975: Age Differences Between Spouses: Trends, Patterns, and Social Implications. In: American Behavioral Scientist 19: 190-205. https://doi.org/10.1177/000276427501900205

Raley, Kelly R.; Sweeney, Megan M. 2020: Divorce, Repartnering, and Stepfamilies: A Decade in Review. In: Journal of Marriage and Family 82,1: 81-99. https://doi.org/10.1111/jomf.12651

Rubin, Bonnie Miller 2016: What Fatherhood Can Be the Second Time Around: More Balanced. In: The Washington Post 14.6.2016 [https://www.washingtonpost.com/ news/parenting/wp/2016/06/14/fatherhood-the-sequel/, 20.8.2019].

Sigle-Rushton, Wendy 2005: Young Fatherhood and Subsequent Disadvantage in the United Kingdom. In: Journal of Marriage and Family 67,3: 735-753. https://doi.org/10.1111/j.1741-3737.2005.00166.x

Sigle, Wendy 2016: Fertility and Population Change in the United Kingdom. In: Rindfuss, Ronald R.; Choe, Minja Kim (Eds.): Low Fertility Institutions, and their Policies: Variations Across Industrialized Countries. Cham: Springer International Press: 77-98. https://doi.org/10.1007/978-3-319-32997-0_4

Sigle, Wendy; Goisis, Alice 2019: Mind the Gap: The Health Advantages that Accompany Parental Marriage Vary by Maternal Nativity. In: Population Studies 73,3: 369-386. https://doi.org/10.1080/00324728.2019.1654613 
Sigle-Rushton, Wendy; Goisis, Alice; Keizer, Renske 2013: Fathers and Fatherhood in the European Union: Data Limitations, Gaps in Knowledge, and Implications for EvidenceBased Policy. In: Tamis-LeMonda, Catherine; Cabrera, Natasha (Eds.): Handbook of Father Involvement: Multidisciplinary Perspectives. $2^{\text {nd }}$ Edition. New York: Routledge: 81-96.

Sigle-Rushton, Wendy; Hobcraft, John; Kiernan, Kathleen K. 2005: Parental Divorce and Subsequent Disadvantage: A Cross-Cohort Comparison. In: Demography 42,3: 427446. https://doi.org/10.1353/dem.2005.0026

Sobotka, Tomáš 2010: Shifting Parenthood to Advanced Reproductive Ages: Trends, Causes and Consequences. In: Tremmel, Joerg (Ed.): A Young Generation Under Pressure? The Financial Situation and the "Rush Hour" of the Cohorts 1970-1985 in a Generational Comparison. Berlin/Heidelberg: Springer-Verlag: 129-154. https://doi.org/10.1007/978-3-642-03483-1_7

Steele, Fiona; Sigle-Rushton, Wendy; Kravdal, Øystein 2009: Consequences of Family Disruption on Children's Educational Outcomes in Norway. In: Demography 46,3: 553 574. https://doi.org/10.1353/dem.0.0063

Sweeney, Meagan M. 2010: Remarriage and Stepfamilies: Strategic Sites for Family Scholarship in the 21st Century. In: Journal of Marriage and Family 72,3: 667-684. https://doi.org/10.1111/j.1741-3737.2010.00724.x

Van Bavel, Jan; Jansen, Mieke; Wijckmans, Belinda 2012: Has divorce become a pronatal force in Europe at the turn of the 21st century? In: Population Research and Policy Review 31: 751-775. https://doi.org/10.1007/s11113-012-9237-6

van de Kaa, Dirk J. 1994: The Second Demographic Transition Revisited: Theories and Expectations. In: Beets, Gijs et al. (Eds.): Population and Family in the Low Countries 1993: Late Fertility and Other Current Issues. Lisse: Swets \& Zeitlinger: 81-126.

Waldenström, Ulla 2016: Postponing Parenthood to Advanced Age. In: Upsala Journal of Medical Sciences 121,4: 235-243. https://doi.org/10.1080/03009734.2016.1201553

Wu, Zheng; Schimmele, Christop M. 2005: Repartnering after First Union Disruption. In: Journal of Marriage and Family 67,1: 27-36.

https://doi.org/10.1111/j.0022-2445.2005.00003.x

Professor Dr. Wendy Sigle ( $₫)$. London School of Economics and Political Science. London. United Kingdom. E-mail: w.sigle@lse.ac.uk

URL: https://www.Ise.ac.uk/gender/people/people-profiles/faculty/wendy-sigle

Professor Dr. Øystein Kravdal. Norwegian Institute of Public Health, Centre for Fertility and Health. Oslo, Norway. E-mail: oystein.kravdal@econ.uio.no URL: https://www.fhi.no/en/more/research-centres/Centre-for-fertility-and-health/ employees/oystein-kravdal/ 


\section{Comparative Population Studies}

WWW.comparativepopulationstudies.de

ISSN: 1869-8980 (Print) - 1869-8999 (Internet)

\section{Published by}

Prof. Dr. Norbert F. Schneider

Federal Institute for Population Research D-65180 Wiesbaden / Germany

\section{(c) BY-SA}

2021

\section{Managing Editor}

Prof. Dr. Johannes Huinink

Dr. Katrin Schiefer

\section{Editorial Assistant}

Beatriz Feiler-Fuchs

Wiebke Hamann

\section{Layout}

Beatriz Feiler-Fuchs

E-mail:cpos@bib.bund.de

\section{Scientific Advisory Board}

Karsten Hank (Cologne)

Michaela Kreyenfeld (Berlin)

Marc Luy (Vienna)

Natalie Nitsche (Rostock)

Zsolt Spéder (Budapest)

Rainer Wehrhahn (Kiel)

\section{Board of Reviewers}

Bruno Arpino (Barcelona)

Kieron Barclay (Rostock)

Laura Bernardi (Lausanne)

Gabriele Doblhammer (Rostock)

Anette Eva Fasang (Berlin)

Michael Feldhaus (Oldenburg)

Tomas Frejka (Sanibel)

Alexia Fürnkranz-Prskawetz (Vienna)

Birgit Glorius (Chemnitz)

Fanny Janssen (Groningen)

Frank Kalter (Mannheim)

Stefanie Kley (Hamburg)

Bernhard Köppen (Koblenz)

Anne-Kristin Kuhnt (Duisburg)

Hill Kulu (St Andrews)

Nadja Milewski (Wiesbaden)

Roland Rau (Rostock)

Thorsten Schneider (Leipzig)

Tomas Sobotka (Vienna)

Jeroen J. A. Spijker (Barcelona)

Heike Trappe (Rostock)

Helga de Valk (The Hague)

Sergi Vidal (Barcelona)

Michael Wagner (Cologne) 